\title{
ДЕДОЛЛАРИЗАЦИЯ РОССИЙСКОЙ ЭКОНОМИКИ: СТАРАЯ ПРОБЛЕМА, НОВЫЕ РЕШЕНИЯ?
}

\begin{abstract}
Аннотация. Новый виток антироссийских санкций в 2018 г. в очередной раз обнажил риски, связанные со сложившейся многолетней зависимостью отечественной экономики от американской валюты. В этой связи задача дедолларизачии выходит на новый уровень и обсуждается в высших эшелонах российской власти. В унисон звучат и заявления многих зарубежных партнёров, пытающихся уйти от растущего экономического давления США. задача дедолларизачии неизбежно возвращает к главной цели, которую вот уже много лет обсуждают отечественные экономисты: структурная перестройка экономики, в результате которой в объёмах производства и экспорте преобладающую роль начала бы играть высокотехнологичная отечественная готовая продукиия, пользующаяся стабильным спросом у наших ведушцих внешнеторговых партнёров. Тактические меры, разработанные российскими финансовыми властями, способны дать толчок процессу дедолларизации, но принципиально решить эту проблему могут только стратегические изменения в национальном хозяйстве.
\end{abstract}

Ключевые слова: Россия, национальная экономика, США, санкиии, дедолларизаџия, Европейский союз, Евразийский экономический союз.

\section{«Вечная» тема}

Задача дедолларизации экономики неоднократно поднималась на протяжении новой истории РФ. Началом современного этапа решения этой проблемы можно считать заявление в феврале 2016 г. руководства Банка России о стремлении дедолларизировать банковскую систему на фоне рисков, которые представляют собой валютные кредиты для компаний, получающих выручку только в рублях.

Снижение доли валютной составляющей должно было коснуться и средств предприятий. Риск, который стремился сократить регулятор, заключается в том, что при резком изменении курса рубля у предприятий, которые получают валютные кредиты, но не имеют при этом валютной выручки, возникают очевидные проблемы с обслуживанием долга. Подобные риски регулятор выявил в наиболее активно растущих секторах экономики: недвижимость и торговля. Совершенно очевидно, что вероятный рост долговой нагрузки в этих секторах в случае резкого изменения курса рубля чреват системными рисками для реального сектора экономики и финансовой системы страны в целом.

Тогда же в качестве инструментального способа решения проблемы ЦБ выбрал повышенные коэффициенты покрытия валютных кредитов капиталом: по всем ссудам и ценным бумагам в иностранной валюте коэффициент повышался до 1,1, по недвижимости - до 1,3, по ценным бумагам нерезидентов - до 1,5.

(C) Гусев Кирилл Нионилович - кандидат экономических наук, ведущий научный сотрудник Центра денежнокредитных и валютно-финансовых проблем Отдела экономических исследований ИЕ РАН. Adpec: 125009, Россия, Москва, ул. Моховая, д. 11, стр. 3. E-mail: banks- europe@ mail.ru.

DOI: http://dx.doi.org/10.15211/vestnikieran62018125131 
В свою очередь, рост значения валюты в банковских балансах был продиктован тем, что значительная часть клиентов конвертировала рублёвые вклады в валютные на фоне неопределённости вокруг курса рубля. Доля валютных депозитов граждан в крупнейших банках превысила 50\% при том, что банки никак не стимулировали этот процесс и, наоборот, пытались его притормозить за счёт низких ставок по валютным вкладам.

Политика ЦБ по снижению привлекательности займов в валюте имела определённый успех, но доля долларов в долгах многих банков тем не менее продолжает оставаться на уровне 60-70\%. Наблюдается и сокращение доли долларов в расчётах, но темпы этого процесса далеки от желаемых. За пять лет с 2013 г. в экспорте сокращение составило 10\% (с 81 до $71 \%$ ), а в импорте - 4\% (с 40 до 36\%). За те же пять лет доля расчётов в рублях за поставки российских товаров и услуг за рубеж увеличилась с 9 до 13\%, а за импорт товаров и услуг в Россию - с 28 до 31\%. В расчётах с Китаем доля доллара до сих пор очень высока: 88\% в экспорте и 74\% в импорте ${ }^{1}$.

\section{Новый поворот}

Сегодня «на помощь» приходят США, которые начали всё агрессивнее вводить санкции против РФ. В этих условиях, с одной стороны, курс рубля становится ещё более волатильным с преобладанием понижательной тенденции, но, с другой, получение кредитов в долларах становится не только ещё менее выгодным, но и еще более рискованным, особенно для всё увеличивающегося числа компаний, попадающих под санкции. К тому же отечественные власти всё чаще стали заявлять, что в ответ на санкции США, Россия будет планомерно отказываться от доллара как платёжного средства.

Пиком волны растущего осознания необходимости снижения зависимости от американской валюты и платёжных систем стал призыв в июне 2018 г. на Международном финансовом конгрессе в Санкт-Петербурге, с которым глава ВТБ А. Костин обратился не только к российскому, но и к международному деловому сообществу. По мнению А. Костина, недостаточно снизить роль доллара в экономике России, необходимо объединять усилия с другими заинтересованными сторонами и вместе стремиться к тому, чтобы позиции американской валюты ослабевали на мировом рынке в целом. «Я думаю, задачу надо ставить глубже - дедолларизация мировой экономики. Пора с долларом начинать бороться в мировом масштабе на самом деле», - сказал Костин ${ }^{2}$.

Глава ВТБ назвал несколько направлений, по которым можно было бы решать озвученную им задачу. Во-первых, вести расчёты с другими странами не в долларах, а в рублях, юанях, евро или национальных валютах государств-контрагентов. Во-вторых, вернуть в российскую юрисдикцию все крупные предприятия, которые действуют в нашей стране, но зарегистрированы в офшорах и ведут свои расчёты в иностранных валютах. В-третьих, перевести на российскую площадку размещение еврооблигаций с заменой в роли первичного депозитария международной клиринговой системы Euroclear на российский аналог. В-четвёртых, стимулировать эмитентов с листингом на иностранных биржах провести листинг акций на Московской бирже с возможностью в дальнейшем отказаться от иностранного листинга. Наконец, создать российский централизованный клиринг драгоценных металлов. Ясно, что все вышеперечисленные меры будут также способствовать росту международного значения российских финансовых площадок.

По мнению А. Костина, отказ от расчётов в долларах может стать неизбежным для мно-

\footnotetext{
${ }_{1}^{1}$ Статистика Банка России. URL: https://www.cbr.ru/statistics/ (дата обращения: 07.10.2018 г.).

${ }^{2}$ Костин: пора начать борьбу с долларом во всем мире. URL: https://www.vestifinance.ru/articles/102480.
} Научно-аналитический вестник ИЕ РАН, 2018, №6 
гих стран мира, если США продолжат использовать свою валюту как экономическое оружие. Процесс вытеснения доллара может занять много времени, но его необходимо начинать уже сейчас. Предложения ВТБ были переданы правительству, все они носят долгосрочный характер и нацелены на изменение существующих мировых тенденций. Но речь идёт не о полном отказе от доллара, а о постепенном увеличении роли рубля в международных расчётах и на финансовых рынках.

Президент РФ В.В. Путин поддержал предложения А. Костина, но уточнил, что Россия не будет полностью отказываться от доллара: РФ будет использовать его «настолько, насколько финансовые власти Соединённых Штатов не будут препятствовать использованию доллара в расчётах» ${ }^{1}$. О «неотказе» от доллара свидетельствует и решение Министерства финансов РФ потратить с 5 октября по 7 ноября 2018 г. рекордную сумму на приобретение валюты в рамках действия нового бюджетного правила, которое работает с февраля 2017 г. Речь идёт о 475 млрд руб. По сложившейся практике валюту для Минфина закупает Центробанк. Но резкие колебания курса рубля с августа 2018 г. вынудили Банк России отказаться от покупки валюты на открытом рынке. Поэтому Минфин до конца года будет покупать валюту напрямую у ЦБ.

Комментируя приостановку закупок на открытом рынке, председатель ЦБ Э. Набиуллина заверила, что это «не означает уменьшения золотовалютных резервов, это означает просто уменьшение темпов их увеличения. Уровень золотовалютных резервов у нас более чем достаточен» ${ }^{2}$ (около 460 млрд долл. ${ }^{3}$ ).

\section{Потенциальные партнёры}

Следует отметить, что идея дедолларизации находит всё большее распространение и на международном уровне. В тот же день, когда В.В. Путин на Восточном экономическом форуме во Владивостоке заявил, что переход на международные расчёты в национальных валютах - «это не политическое задание, это экономическая задача» ${ }^{4}$, председатель Еврокомиссии Жан-Клод Юнкер в Страсбурге призвал сделать евро реальным соперником доллара в качестве мировой резервной валюты.

К отказу от доллара подталкивает агрессивная экономическая политика, которую администрация Д. Трампа развернула в отношении своих ключевых конкурентов на мировом рынке. Потенциал доллара как средства экономического давления долгое время оставался в тени тех удобств, которые предоставляла эта валюта в качестве средства международных расчётов и ведущего компонента официальных золото-валютных резервов государств.

Собственно, и сегодня мнения экономистов и бизнесменов относительно реализуемости самой идеи дедолларизации заметно разнятся. Многие считают, что только санкции вынудили отечественные финансовые власти по-настоящему начать думать об этом. И если Россия будет пытаться переформатировать международную финансовую систему в одиночку, то успеха это не принесёт, потому что по-настоящему заинтересованных партнёров у РФ в этом деле сейчас не так уж и много. Среди них Иран и, возможно, в какой-то степени Европа, у которой, правда, есть свой интерес, состоящий в повышении международной роли евро.

Что касается стран БРИКС, то тут наиболее вероятным партнёром мог бы оказаться Ки-

\footnotetext{
${ }_{2}^{1}$ Путин считает ошибкой США ограничения на расчёты в долларах. URL: https://tass.ru/ekonomika/5409088.

Набиуллина рассказала, когда ЦБ вернётся к покупкам валюты для Минфина. URL: https://ria.ru/ economy/20180914/1528591522.html.

${ }_{4}^{3}$ Статистика Банка России. URL: https://www.cbr.ru/statistics/ (дата обращения: 07.10.2018 г.).

4 Путин объяснил важность перехода на расчёты в нацвалюте. URL: https://iz.ru/788110/2018-09-12/putinobiasnil-vazhnost-perekhoda-na-raschety-v-natcvaliute.
} 
тай, который сейчас находится в состоянии торговой конфронтации с США, и чья национальная валюта потенциально могла бы играть ведущую роль, если не в мире, то, как минимум, в Евразии. Но и тут не всё так очевидно, потому что Китай, скорее, присоединяется к американским санкциям против России, чем противостоит им. Да и колоссальные официальные резервы КНР, значительная часть которых имеет американское происхождение, не оставляют значительного поля для манёвра.

В аналогичной взаимозависимости с США находятся и другие страны БРИКС - Бразилия, Индия и ЮАР, поэтому вряд ли кто-либо из них в одиночку станет делать резкие движения против доллара. С другой стороны, именно у этой группы стран по экономическому потенциалу сейчас больше всего шансов вместе противопоставить некое коллективное решение, которое могло бы составить действенную конкуренцию доллару. Естественно, это решение не будет сиюминутным, оно должно вытекать из эволюционной логики развития БРИКС как интеграционного объединения. Наиболее логичным было бы начать с создания системы взаимных расчётов на базе национальных валют стран-участниц, в которую со временем можно было бы вовлечь региональные объединения, которые строятся вокруг каждой из стран БРИКС. В случае с Россией речь, безусловно, идёт о ЕАЭС.

Ключевым внешнеторговым партнёром России остаётся Евросоюз. Но в случае с ним сейчас сложно рассчитывать на какой-то вариант, кроме перехода во взаимной торговле на евро. Для Европы это было бы важным подспорьем в повышении международной роли единой валюты. Но шансы евро «вытеснить» доллар пока не слишком высоки. Долговой кризис в Европейском союзе показал, что странам союза предстоит пройти ещё очень длинный путь в плане приведения их финансовых, фискальных и банковских систем к тому же уровню согласованности и чёткости, которым сейчас отличается ФРС США.

Среди возможных новых санкций против России сейчас обсуждается запрет расчётов в долларах за российскую нефть. В этом случае Европа, которая является крупнейшим импортёром отечественных углеводородов, будет поставлена перед сложным выбором: следовать в фарватере США либо следовать своим экономическим интересам и переводить расчёты за российское сырьё в евро и рубли. При всех политических и экономических трудностях, сопряжённых с реализацией второго варианта, в долгосрочном плане он весьма выгоден для Европы.

Схожим образом выглядит и угроза отключения от международной системы SWIFT. Аналоги этой системы уже создаются в России, Китае, Иране. Не исключено, что к собственной подобной системе придёт и Европа.

\section{Что делать?}

Универсальный сценарий защиты от доллара и повышения международной роли любой национальной валюты включает в себя набор достаточно очевидных с теоретической, но сложных с практической точки зрения шагов: стимулирование основных торговых партнёров к использованию во взаимных расчётах национальных валют вместо платёжных средств третьих стран; создание собственных независимых платёжных систем; защита внутреннего рын-ка, замещение валютного импорта национальным производством аналогичных товаров, расширение экспорта.

Кроме того, очевидно, что в международных расчётах страны не будут использовать валюту, курс которой нестабилен, в том числе из-за ошибочных решений денежно-кредитного регулятора государства-эмитента. Поскольку подобная ситуация нередко наблюдается в России, назрела необходимость разработки системы мер, которые не только учитывали бы пре- 
жние ошибки, приводившие к обесценению рубля, но и могли бы предвосхищать возможные негативные воздействия будущих внешних шоков.

Важную психологическую роль могло бы сыграть и укрепление рубля относительно ведущих мировых валют. Предпосылки для этого есть: многие отечественные экономисты сходятся во мнении, что реальная стоимость рубля выше его нынешнего курса и находится на уровне 50-60 рублей за доллар. Понятно, что серьёзное понижательное давление на курс сейчас оказывает угроза все новых санкций со стороны США, но при должной защите от внешних шоков влияние этого фактора можно было бы нивелировать.

Одновре́менно необходимо отказаться от ошибочной многолетней доктрины, продиктованной интересами крупных отечественных компаний-экспортёров, согласно которой для экономического роста необходим дешёвый рубль. Наоборот, если речь идёт о выдвижении рубля на роль международной валюты и интересах населения страны, которое получает доход и расплачивается в рублях, укрепление национальной валюты более чем желательно. При этом не стоит забывать, что в новейшей истории России укрепление рубля нередко совпадало с периодами роста экономики.

Экономические власти страны, в лице замминистра финансов Алексея Моисеева, уже заверяют, что Россия сможет достичь существенного прогресса в дедолларизации через 1,5-2 года. В том числе потому, что в этом направлении есть неплохой задел: до 60\% торговли со странами бывшего СССР уже ведётся в рублях ${ }^{1}$. При этом понятно, что необходимо продвигать рубль как платёжное средство и на более отдалённые рынки, параллельно отказываясь от расчётов в валютах третьих стран внутри уже сформировавшихся интеграционных объединений с участием РФ, прежде всего ЕАЭС.

Но есть и скептики. Например, глава совета директоров Альфа-банка Петр Авен считает отказ от доллара крайне неэффективной мерой, потому что в мировой торговле альтернативы доллару нет, и отказ от него приведёт к колоссальным инфляционным издержкам². Председатель Счётной палаты Алексей Кудрин считает, что Россия сможет проводить в национальных валютах только часть сделок, и только со странами с «мягкими валютами», к которым относится, например, китайский юань. «Рубли, как известно, не имеют на рынке такую ликвидность, как другие резервные валюты. Вот почему не все захотят переходить на рубль, это дополнительные издержки» ${ }^{3}$. А Россия не сможет полностью отказаться от доллара и евро в своих внешних расчётах, потому что вынуждена закупать многие товары и технологии, которые продаются только за резервные валюты.

\section{Выводы}

В практическом плане задача правительства сейчас заключается в разработке мер по снижению зависимости отечественной экономики от доллара, в первую очередь, через создание реальных стимулов для перехода внешнеторговых расчётов российских компаний на национальные валюты. План дедолларизации уже вынесен на рассмотрение правительства. Речь, прежде всего, идет о преференциях для экспортёров, использующих рублёвые расчёты: ускоренный возврат НДС для экспортных поставок, постепенная отмена нормы об обязательной репатриации экспортной рублёвой выручки.

\footnotetext{
1 Минфин считает, что радикальный прогресс в дедолларизации возможен через 1,5-2 года. URL: https://tass.ru/ekonomika/5562097.

2 Глава совета директоров Альфа-Банка назвал отказ от доллара заменой топора на шкуру. URL: https://www.dp.ru/a/2018/10/04/Glava soveta direktorov.

3 Кудрин поддержал идею о внешней торговле в национальных валютах. URL: https://www.rbc.ru/ rbcfreenews/5bb47f6e9a794720b43fcc09.
}

Научно-аналитический вестник ИЕ РАН, 2018, №6 
Оценивая перспективность предложений по повышению международной роли рубля (и, соответственно, номинированных в нём ценных бумаг), стоит обратить внимание на то, что осенью 2018 г. Минфин в ходе первого после перерыва, вызванного волатильностью рубля, аукциона ОФЗ сумел разместить только 7,4 млрд руб. из запланированных 20 млрд руб. При этом спроса на трёхлетние облигации вообще не было. Очевидно, итоги аукциона напрямую обусловлены рисками, связанными с введением новых санкций и дальнейшим ослаблением курса рубля. В этой связи ясно, что принципиальное изменение ситуации возможно только в случае значительного роста доверия к рублю на фоне снижения волатильности и роста курса отечественной валюты.

Можно предположить, что реализация мер по дедолларизации приведёт к росту несырьевого экспорта. В то же время, пока доля сырья в отечественном экспорте остаётся высокой, а цены на него традиционно формируются в долларах, говорит о принципиальном решении задачи дедолларизации невозможно.

Таким образом, задача дедолларизации неизбежно возвращает к главной цели, которую вот уже много лет обсуждают отечественные экономисты: структурная перестройка экономики, в результате которой в объёмах производства и экспорте преобладающую роль начала бы играть высокотехнологичная отечественная готовая продукция, пользующаяся стабильным спросом у наших ведущих внешнеторговых партнёров. Тактические меры, разработанные российскими финансовыми властями, способны дать толчок процессу дедолларизации, но принципиально решить эту проблему могут только стратегические изменения в национальном хозяйстве.

\section{Список литературы}

Статистика Банка России. URL: https://www.cbr.ru/statistics/

Костин: пора начать борьбу с долларом во всём мире. URL: https://www.vestifinance. ru/articles/102480.

Путин считает ошибкой США ограничения на расчёты в долларах. URL: https://tass.ru/ ekonomika/5409088.

Набиуллина рассказала, когда ЦБ вернётся к покупкам валюты для Минфина. URL: https://ria.ru/economy/20180914/1528591522.html.

Путин объяснил важность перехода на расчёты в нацвалюте. URL: https://iz.ru/788110/ 2018-09-12/putin-obiasnil-vazhnost-perekhoda-na-raschety-v-natcvaliute.

Минфин считает, что радикальный прогресс в дедолларизации возможен через 1,5-2 года. URL: https://tass.ru/ekonomika/5562097.

Глава совета директоров Альфа-Банка назвал отказ от доллара заменой топора на шкуру. URL: https://www.dp.ru/a/2018/10/04/Glava_soveta_direktorov.

Кудрин поддержал идею о внешней торговле в национальных валютах. URL: https://www.rbc.ru/rbcfreenews/5bb47f6e9a794720b43fcc09.

\section{References}

Statistika Banka Rossii. URL: https://www.cbr.ru/statistics/

Kostin: pora nachinat borbu $\mathrm{s}$ dollarom vo vsem mire. URL: https://www.vestifinance.ru/articles/102480.

Putin schitaet oshibkoy SSHA ogranicheniya na raschety $\mathrm{v}$ dollarah. URL: https://tass.ru/ekonomika/5409088. 
Nabiullina rasskazala, kogda $\mathrm{CB}$ vernetsya $\mathrm{k}$ pokupkam valuty dlya Minfina. URL: https://ria.ru/economy/20180914/1528591522.html.

Putin obyasnil vazhnost perekhoda na raschety v natzvalute. URL: https://iz.ru/788110/2018-0912/putin-obiasnil-vazhnost-perekhoda-na-raschety-v-natcvaliute.

Minfin schitaet, chto radikalniy progress v dedollarizatzii vozmozhen cherez 1,5-2 goda. URL: https://tass.ru/ekonomika/5562097.

Glava soveta direktorov Alfa-Banka nazval otkaz ot dollara zamenoy topora na shkuru. URL: https://www.dp.ru/a/2018/10/04/Glava_soveta_direktorov.

Kudrin podderzhal ideyu o vneshney torgovle $\mathrm{v}$ natzionalnih valutah. URL: https://www.rbc.ru/rbcfreenews/5bb47f6e9a794720b43fcc09.

\section{Dedollarization of the Russian economy: old problem, new solutions?}

Author. Kirill Gusev, Candidate of Sciences (Economics), Leading Research Associate, Center of Monetary and Financial Studies, Institute of Europe, Russian Academy of Sciences. Address: 11-3, Mokhovaya str., Moscow, Russia, 125009. E-mail: banks-europe@ mail.ru.

Abstract. The new round of anti-Russia sanctions in 2018 once again revealed the risks of the long-term dependence of the Russian economy on the US dollar. The task of dedollarization is gaining new momentum and is being discussed by the highest officials in Russia, backed up by the statements of many foreign partners, trying to avoid the growing economic pressure of the USA.

Key words: Russia, national economy, USA, sanctions, dedollarization, European Union, Eurasian Economic Union.

DOI: http://dx.doi.org/10.15211/vestnikieran62018125131 